\title{
TENDÊNCIAS REGULATÓRIAS E IMPACTOS NAS DESIGUALDADES EDUCACIONAIS*
}

\begin{abstract}
Almerindo Janela Afonso
RESUMO: Nas últimas décadas, o léxico das ciências sociais tem sido enriquecido e reatualizado, permitindo, apesar de algum evidente sincretismo e da frequente polissemia de muitos dos termos mais mencionados, dar maior densidade às análises das mudanças contemporâneas, nomeadamente no campo das políticas para a educação. No que diz respeito a este texto, discute-se como isso acontece com os conceitos de regulaçáo, governança e accountability. Trata-se, nesse caso, de uma parte da investigação que procura enunciar, ainda que de forma sumária, algumas interfaces e articulaçóes dos conceitos referidos e implicaçóes e impactos que a partir daí podem ser relacionados com as desigualdades educacionais.
\end{abstract}

Palavras-chave: Regulação. Regulaçôes. Governança. Accountability. Desigualdades educacionais.

\section{TRENDS IN REGULATIONS AND IMPACTS ON EDUCATIONAL INEQUALITIES}

ABSTRACT: In the last decades, the lexicon of social sciences has been somewhat enriched and updated and, despite some clear syncretism and the polysemy often found among the most used terms, this has made it possible to create more solid analyses of contemporary changes, particularly in the field of education policy. As far as this text is concerned, this is what happens with the concepts of regulation, governance and accountability. In this case, this is part of the research that seeks to lay out, relatively briefly, some interfaces and connections among the above-mentioned concepts, and some of the implications and impacts that may exist for educational inequalities.

Keywords: Regulation. Regulations. Governance. Accountability. Educational inequalities.

\footnotetext{
*Este artigo insere-se no projeto Políticas, Governação e Administração da Educação - Educação 3D - Democracia, Desigualdade e Diferença e é financiado pelo Centro de Investigação em Educação (CIEd), projetos UID/CED/1661/2013 e UID/CED/1661/2016, Universidade do Minho, Instituto de Educação, por meio de fundos nacionais da Fundação para a Ciência e a Tecnologia/do Ministério da Educação e Ciência de Portugal (FCT/MCTES-PT).

${ }^{1}$ Universidade do Minho, Instituto de Educação, Departamento de Ciências Sociais da Educação - Braga, Portugal. E-mail: ajafonso@ie.uminho.pt DOI: $10.1590 / \mathrm{ES} 0101-73302019220116$
} 


\title{
TENDENCIAS REGULATORIAS Y LOS IMPACTOS SOBRE LAS DESIGUALDADES EDUCATIVAS
}

\begin{abstract}
RESUMEN: En las últimas décadas, el léxico de las ciencias sociales se ha enriquecido y actualizado, permitiendo que sean analizados el sincretismo de la polisemia frecuente de muchos de los términos más utilizados para la educación. En lo que respecta a este texto, esto es lo que sucede con los conceptos de regulación, gobernanza y responsabilización. Más precisamente, en este caso, esto es parte de la investigación que busca enunciar, aunque de manera relativamente breve, algunas interfaces y articulaciones de los conceptos anteriores, y algunas de las implicaciones e impactos que pueden estar relacionados con las desigualdades educativas.
\end{abstract}

Palabras clave: Regulación. Regulaciones. Gobernanza. Responsabilización. Desigualdades educativas.

\section{Introdução}

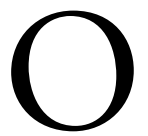

título deste artigo poderia ser interpretado e desenvolvido de formas muito distintas, uma vez que o termo regulação tem diversos significados, múltiplas derivaçôes e usos, muitos deles disseminados por disciplinas e análises que enfatizam diferentes perspectivas, umas mais descritivas, críticas e problematizadoras, outras mais propositivas e normativas, ainda que, por vezes, elas sejam parcialmente referenciadas ou coexistam nos mesmos textos e discursos. Numa breve revisão da literatura, encontram-se referências a regulação, desregulação, re-regulação, multi-regulação, regulação de regulaçôes, meta-regulação, contra-regulação, "transversalidade das regulações" (BARROSO, 2018), micro-regulação, não regulação etc., estando cada designação dependente dos atores/agentes, instrumentos e dispositivos envolvidos ou privilegiados nos processos de regulação, ou das configuraçôes, interpretaçóes e níveis em que eles ocorrem (institucional, comunitário, municipal, nacional, regional, global etc.), entre outros critérios. Esses processos, frequentemente internos e no âmbito da autonomia relativa dos Estados nação, passaram, nas últimas décadas e de forma crescente, a coexistir e a interagir de diversos modos (por vezes até de forma subordinada) com processos e dispositivos de regulação supranacional e de regulação multinível.

Ao longo da modernidade histórica (sobretudo depois do Tratado de Vestfália e de outros tratados que reforçaram as pretensóes de soberania), o Estado, enquanto aparelho político-administrativo, foi assumindo em vários setores da vida social a função primordial de regulação no contexto nacional. 
Assim, a regulação para o controle social (em sentido lato) e a regulação do próprio mercado, em sentido mais restrito, têm sido e continuam a ser funçôes exercidas pelo Estado, embora ao longo do tempo ocorram com diferentes justificaçôes político-ideológicas, intensidades muito distintas e diversificados recursos, em termos de instrumentos e estratégias. $\mathrm{O}$ exemplo mais frequente remete para as experiências e conjunturas históricas em que o keynesianismo predominou (inicialmente, por meio das políticas do new deal nos Estados Unidos, na década de 1930, e, mais tarde, após a Segunda Guerra Mundial, sobretudo com a criação e o desenvolvimento dos modelos nórdicos ou social-democratas de Estado de Bem-Estar Social). Todavia, em muitos países com economia de mercado, dependendo do seu lugar no sistema mundial e das diferenças ou especificidades de cada caso, o impacto das agendas globais hoje dominantes tem sido marcado por mudanças profundas, começando por constatar-se a redefinição de muitas das funçôes tradicionais do Estado, a retração das políticas públicas e, de forma mais ou menos sincrônica, a defesa da maior eficácia de um mercado desregulado, cuja versão mais ortodoxa parece desejar a coexistência com um Estado minimo ou ultramínimo (ver, a esse propósito, por exemplo, NOZICK, 2009).

Se esse Estado diminuído ou muito reduzido a certas funções tivesse sido concretizado, dando materialidade aos discursos e às justificaçōes político-ideológicas dos seus defensores, estaríamos assistindo não apenas ao que hoje já consideramos como protagonismo exacerbado do mercado (e das lógicas e valores que lhe são intrínsecos), mas também à sua quase exclusividade (ou mesmo monopólio) enquanto fundamento de regulaçâo social. As realidades, porém, foram e são mais heterogêneas e complexas. Dois breves exemplos. Depois do 11 de setembro de 2001, os Estados tenderam, em geral, a reforçar o seu poder de coerção física e a sofisticar e ampliar os meios de vigilância panóptica sobre os cidadáos, tornando-se mais fortes e competitivos. Isso por meio de investimentos públicos na segurança interna e na indústria bélica, de tal forma que voltaríamos a ouvir falar de uma espécie de novo keynesianismo militar, também já designado "capitalismo de vigilância", na expressão recente de Zuboff (2019), cuja variante mais conhecida e desumana, nesse último caso, é a atual exigência do presidente Trump para que sejam aprovados gastos extraordinários para construir um muro na fronteira com o México, para impedir a passagem de emigrantes e refugiados. Os direitos humanos parece que deixaram de ser (pelo menos por agora) estrategicamente convocados para justificar decisóes de algumas das principais potências mundiais, ao contrário do que foi usual noutras situaçóes, como aconteceu na guerra do Kosovo, quando Chomsky (2002) criticou o que entáo chamou de "o novo humanismo militar". Algo de estranho acontece também quando, conforme as lógicas atuais do capitalismo mais agressivo e da simultânea retração e fragilização da democracia representativa, são os próprios poderes dominantes que abrem brechas nas regras estruturantes 
do neoliberalismo, supostamente baseado na salutar competição dos mercados desregulados. Do mesmo modo, é inesperado o que ocorre quando se recupera o protecionismo econômico imposto pela atual administração norte-americana, ou quando se decide o Brexit, em relação à pretendida saída da Inglaterra da Uniáo Europeia, que náo deixam de significar a vontade de reassumir uma parte importante do poder de regulação dos mercados (e não só) por parte dos respectivos Estados nacionais. Todavia, paradoxalmente, noutras situaçóes, se a corrente econômica mainstream ainda continua a ter condiçóes para a sua expansão (como é o caso do setor financeiro), isso também não é indiferente à conivência ou mesmo indução do Estado, ainda que esse poder de regulaçáo possa ser mitigado ou se exerça por delegação, como acontece com a proliferação de agências reguladoras.

\section{Regulação, Estado regulador, Estado avaliador}

Apesar disso, a expansão da mercadorização de várias dimensões do mundo da vida parece imparável, ao mesmo tempo em que se mantém grande opacidade dos mecanismos de regulação que suportam, por exemplo, o crescente protagonismo do sistema financeiro e, no caso que mais impacta a educação, as formas mais ardilosas de privatizaçâo do público, nomeadamente, "por processos de criação de estatutos organizacionais fluidos e de regimes jurídicos híbridos, combinando direito público e direito privado, administração pública e gestão empresarial" (LIMA, 2018, p. 130), ou mesmo o escasso escrutínio e a baixa reflexividade (desde logo nas instituições de ensino superior) sobre as consequências do capitalismo cognitivo e da nova economia do conhecimento.

São esses alguns dos motivos que interrogam a eficácia das funções tradicionais do Estado em diferentes países, explicando, pelo menos em parte, a emergência de outros atores que disputam a função de regulação, num mundo onde o aumento da complexidade, da incerteza e da imprevisibilidade exige novas formas de agir, de modo a manter a expansão do processo de acumulação, sem, todavia, deixar de ter em conta a necessidade de padróes aceitáveis de coesão social. Nesse sentido, a definição de regulação tornou-se ela própria mais complexa e polissêmica, desde a economia à educação, e governar (enquanto ação do governo) passou a diferenciar-se de governação (enquanto governance) - designação profusamente traduzida, com algumas nuanças, como governança, nova governança ou governância - , querendo genericamente significar que uma diversidade de atores está envolvida em múltiplos processos de regulaçáo (ou numa regulaçáo multiescalar) que já não se referenciam exclusiva ou predominantemente ao Estado nacional, ainda que este não deixe de estar ativamente presente. 
Há, portanto, articulaçóes e interfaces complexas e contraditórias entre governança e regulação que são deveras pertinentes em termos analíticos, acima de tudo para quem estuda as políticas educacionais. Na definição da agenda educativa estão hoje envolvidos muitos e diferentes níveis e parceiros para além dos governos nacionais e das organizaçóes supranacionais. Por esse ângulo, de forma sucinta, "governança está relacionada com a problemática da coordenação, enquanto regulação aparece associada à variabilidade e à reprodução de um dado sistema social" (Reis, 2013, p. 107). Numa síntese de alguns autores regulacionistas, outra autora esclarece que

a regulaçâo pode ser entendida como o conjunto de atividades [...] orientadas para produzir essa congruência de comportamentos individuais e coletivos, para mediar os conflitos sociais e para limitar as distorçóes, produzidas pelo processo de acumulação, a níveis compatíveis com a coesáo social (Antunes, 2007, p. 7).

Assim sendo, as políticas educacionais, enquanto políticas públicas, podem, entre outras funçóes, contribuir para assegurar a estabilidade de determinado regime de acumulação e de dada configuração de ordem social (ou coesão social) e, nessa lógica, têm a ver com o modo de regulaçáo dominante em certa conjuntura ou período histórico. Por outro lado, quer por referência à transiçáo do fordismo para o pós-fordismo, quer por referência à globalização e internacionalização da economia, quer por referência à crise do Estado (sobretudo do Estado de Bem-Estar Social enquanto Estado interventor), ou ainda, pelo processo de europeização, como no caso discutido por Majone (1999), a regulação aparece cada vez mais associada a uma nova forma de atuação do Estado: o Estado regulador.

$\mathrm{Na}$ perspectiva de Majone (1999), por exemplo, ao passo que o Estado interventor conta com uma administração burocrática centralizada, "o Estado regulador depende da extensa delegação de poderes a instituiçóes independentes: agências reguladoras ou comissões" (Majone, 1999, p. 1). No caso da educação, para Barroso (2005), a expressão Estado regulador transmite igualmente a ideia de "um Estado menos prescritivo e regulamentador e de uma 'nova administração pública' que substitui um controlo directo e a priori sobre os processos, por um controlo remoto, e a posteriori baseado nos resultados" (Barroso, 2005, p. 732). Aliás, aquilo que já se chama a agencificação da administração pública está, portanto, em linha com a introdução do new public management (García-Juanatey et al., 2017, p. 62). No entanto, mesmo quando deixou de ser provedor direto de determinados serviços públicos e assumiu a privatização, o Estado procurou, em muitos casos, salvaguardar o interesse público impondo condições às organizaçóes privadas e criando entidades reguladoras independentes - decisão, porém, que não deixa de ser algo paradoxal porque o Estado 
"renuncia ao exercício, por si próprio, dessa função reguladora, inventada para responder à necessidade de, perante a privatização do próprio Estado, salvaguardar o interesse público" (NUNES, 2007, p.14). Na esteira de outros autores, Sguissardi (2013) resume bem esses dilemas quando escreve: "Pode-se afirmar que o Estado regulador é capturado pelo que deve ser regulado" (Sguissardi, 2013, p. 953, grifo do autor).

A entrega das tarefas de regulação a entidades independentes do Estado passou a dirigir-se também a muitos outros domínios para além da economia em sentido restrito, alargando-se a bens e serviços coletivos, como é o caso da saúde e da educação, e cada vez mais aos problemas ecológicos e ambientais, para os quais Beck (1992) há muito chamou a atenção, ao refletir sociologicamente sobre a sociedade de risco. Se o Estado não assumisse a regulação das regulaçóes ou a meta-regulação, talvez estivéssemos mesmo perante um pseudoEstado regulador quando falamos de Estado regulador, uma vez que, ao transferir cada vez mais a função de regulação para autoridades reguladoras independentes ficaria sem essa função.

Embora em diversos domínios de atividade, sobretudo no campo da economia, as agências reguladoras já tenham há muito tempo forte presença e visibilidade social crescente, no campo da educação elas também existem, podendo ser salientado, a título de exemplo, os casos mais conhecidos do Sistema Nacional de Avaliação da Educação Superior (Sinaes) e da eventual criação no Brasil de um novo Instituto Nacional de Supervisão e Avaliação da Educação Superior (Insaes) e, em Portugal, o caso da já consolidada Agência de Avaliação e Acreditação do Ensino Superior (A3ES).

No que diz respeito à educação em Portugal, a A3ES é o exemplo paradigmático de uma entidade independente de regulação que desenvolve, no panorama das instituiçóes de ensino nesse país, o modelo mais avançado ou completo de accountability, porque consubstancia de forma articulada os três pilares fundamentais constituídos da avaliação, da prestação de contas e da responsabilização, com impacto forte no que se refere às recomendaçóes e decisóes que emite (AFONSO, 2013a), tendo além disso a responsabilidade, de acordo com o normativo legal da sua criação, "pela inserção de Portugal no sistema europeu de garantia da qualidade do ensino superior" (Decreto-Lei no 369/2007, de 5 de novembro). Esse modelo institucional não é perfeito (não existem modelos perfeitos), e por isso é discutível em várias das suas dimensóes, nomeadamente quanto ao cabal cumprimento da expectativa de que uma agência de regulaçáo como essa terá de ter como um dos pilares a expertise em avaliação dos seus profissionais, o que talvez apenas em parte esteja garantido ${ }^{1}$. Por outro lado, deve-se levar em conta o poder (e as consequências do exercício do poder) de uma nova tecnocracia que muitas vezes se constitui nessas agências de regulação tendo apenas o conhecimento especializado como base de legitimação. Nesse senti- 
do, quando se considera que uma vantagem das agências de regulação está, em grande medida, no fato de serem organizaçôes em que o poder dos especialistas é estruturante, ganha importância a observação de Yeung (2010) quando levanta a questão da eventual tensão "entre a imagem da regulação como um processo tecnocrático e apolítico [...] e o reconhecimento de que decisóes regulatórias invariavelmente têm dimensóes políticas e, portanto, requerem legitimação democrática" (YEUNG, 2010, p. 64).

Outra questão que se deixa sinalizada para futuro aprofundamento (e que, aliás, é bastante recorrente na literatura sobre as agências reguladoras) é a questão da transparência e da prestação de contas do trabalho que é efetuado por essas organizaçôes, as quais não podem deixar de ser escrutinadas por meio do exercício legítimo do controle social que se exerce (ou deve exercer) sobre essas agências (LODGE; STIRTON, 2010). Assim, seria importante perceber se a prestação de contas e a transparência dos processos e decisões sobre a avaliação e a acreditação das instituiçóes de ensino superior em Portugal (tão criticadas em modelos anteriores) aumentaram ou diminuíram com a A3ES e como os dirigentes e demais responsáveis percebem os graus de autonomia que têm, não apenas em relação a órgãos governamentais de referência para a sua atuação, como no tocante às próprias instituiçóes de ensino superior, nomeadamente as que têm estatuto jurídico de fundação².

A regulação ocorre muitas vezes em contextos de forte ambiguidade política e de intencionalidades difusas e contraditórias, razão por que nem sempre se consegue perceber as verdadeiras motivaçóes que estão por trás de algumas propostas, como a que diz respeito à criação do Insaes, que começou a tramitar em 2012 no Congresso Nacional brasileiro. Nesse sentido, mesmo tendo em conta que pode se tratar de uma política de Estado, uma das questóes que se coloca é a de que a regulação estatal, por meio dessa agência "ainda assim carregaria consigo o ônus das contradiçóes com que este convive nas suas relaçóes com os interesses dos polos público e privado/mercantil no seu interior" (SGUISSARDI, 2013, p. 957).

Em qualquer dos casos, o Estado regulador, na medida em que está mais interessado nos resultados do que nos processos, não se distingue, no tocante à avaliação do Estado avaliador. A avaliação é aqui claramente assumida como um instrumento de regulação. Em muitos países, os sistemas educativos nacionais, como no caso ainda do sistema de ensino em Portugal, foram durante muito tempo regulados de modo predominante pela orientação administrativo-burocrática, tendo o Estado como principal protagonista, desde logo na definição dos objetivos curriculares e educacionais e respectivos sistemas de avaliação.

Num contexto mais amplo, o Estado avaliador (designação que começou a ser referenciada por Guy Neave para o ensino superior) diversificou-se 
posteriormente, sendo possível distinguir, até o momento, três mudanças ou etapas fundamentais (AFONSO, 2013b): a fase predominantemente nacional (regulaçáo pelo Estado mediante exames ou testes externos estandardizados); a fase de presença e interferência crescente das organizaçóes internacionais ou supranacionais - regulação por peritos de organizaçóes que se assumem como think tanks na educação e em avaliaçôes comparadas estandardizadas, como a Organização para a Cooperação e Desenvolvimento Econômico (OCDE), e indução internacional na constituição de agências de regulação nacional no ensino superior, promovida pela European Association for Quality Assurance in Higher Education (ENQA). No contexto europeu, por exemplo, pode-se perceber melhor porque é que "o processo de Bolonha inaugura uma fase e constitui uma modalidade inédita na regulação supranacional da educação" (ANTUNES, 2005, p. 134, grifo do autor). Por último, temos a fase que designei provisoriamente de pós-Estado avaliador, caracterizada pela desregulação internacional, com crescente radicalização dos processos de mercadorização da educação superior, que constituem mudanças profundas para as quais vários autores têm convincentemente chamado a atenção (entre outros, ver BIANCHETTI; SGUISSARDI, 2017).

Salienta-se para os objetivos deste texto que o Estado avaliador é ainda congruente com modelos de regulação pós-burocráticos (BARROSO, 2005). Nos últimos anos, um dos aspectos mais expressivos dos novos modos de regulação no campo da educação, num número cada vez maior de países, está relacionado à mudança de uma regulação baseada em objetivos definidos a priori para uma regulação fundamentada em resultados (outcomes) - também designada como regulação baseada no conhecimento ou regulação pós-burocrática, de que o Programme for International Student Assessment (Pisa) é o exemplo mais conhecido e com maior impacto. Mais especificamente, "nos modos de intervenção da OCDE no âmbito do Pisa encontram-se os traços fortes de uma regulação transnacional" (CARVALHO, 2016, p. 674).

Do mesmo modo, no que tange à avaliação institucional, alguns autores portugueses não hesitam em afirmar que a avaliação externa das escolas (do ensino não superior), embora com especificidades nacionais, tem determinada configuração europeia que traduz a "ampla difusão e relevância” de processos de regulação pós-burocráticos. No caso português, mais concretamente, estamos perante certa "hibridização", que se traduz na "combinação de modos regulatórios transnacionais e nacionais [e na] coexistência em âmbito nacional de formas burocráticas e pós-burocráticas de regulação" (CARVALHO; COSTA, 2017, p. 686) ${ }^{3}$.

No que diz respeito à questão das desigualdades (nesse caso, desigualdades e assimetrias educacionais), é importante considerar a existência de relaçóes complexas e contraditórias quando as cruzamos com as formas e os pro- 
cessos de regulação tradicionais e os novos processos regulatórios dos sistemas educativos. Assim, pode-se perguntar: são os processos de regulação burocráticos ou hiperburocráticos mais indutores de desigualdades do que os processos pós-burocráticos? E os modelos híbridos? Essa é uma questão pertinente, mas que fica aqui apenas sinalizada.

Finalmente, uma observação sobre as políticas de accountability em educação. Alguns trabalhos têm sublinhado que essas políticas (já é frequente serem referenciadas como um dos pilares da agenda global para a educação) têm contribuído para transformar os modos de regulação da educação (FALABELLA; VEGA, 2016). Nessa visão, tem-se a afirmação de que "a accountability é uma dimensão-chave da governança regulatória" (JORDANA; BIANCULLI; FERNÁNDEZ-I-MARÍN, 2015, p. 1). A relação entre regulação, governança e accountability é, de qualquer modo, complexa. Na minha perspectiva, a accountability pode ser entendida e problematizada como dispositivo de regulação porque, tendo amplitude maior do que a avaliação, nomeadamente na dimensão enforcement, pode ser mais eficaz quando se pretende que sejam atingidos determinados objetivos convergentes com o funcionamento do sistema capitalista, com dada concepção e prática de democracia política e com a indução de certos padróes de coesão social ${ }^{4}$. Corroborando, pelo menos em parte, essa afirmação, Olsen (2018, p. 1) escreve: "As democracias modernas vivem com conflitos náo resolvidos e os regimes de accountability fazem parte de um arranjo institucional para preservar a ordem e a continuidade e também para criar dinâmicas e mudança”. Em síntese, entre muitos outros aspectos, tanto os processos de regulação como as formas de governança e os modelos e dispositivos de accountability partilham dimensôes técnicas e políticas, e será inevitável traduzir isso em relaçóes complexas, e frequentemente contraditórias, e em tensóes permanentes que valerá a pena considerar mais demoradamente em futuras análises.

\section{(Des)regulação e desigualdades sociais e educacionais}

Volto agora a meados dos anos 1990 e à primeira década dos anos 2000 para lembrar que em muitos países a crise do modelo keynesiano (ou, mais amplamente, a crise estrutural do Estado) e a expansão do mercado (sobretudo via privatização e mercantilização do público) tornaram mais explícito o agravamento dos déficits de oportunidades, criando novas e profundas assimetrias e desigualdades sociais, econômicas e educacionais. Nesse contexto, emerge um renovado apelo (em grande medida compensatório) à comunidade (designada também sociedade civil, terceiro setor ou público não estatal). Tudo isso ainda no contexto nacional e com expressóes próprias consoante aos casos. O público não estatal foi teorizado no Brasil por alguns economistas co- 
nhecidos, como Bresser Pereira, e ganhou centralidade no campo educacional por interessantes análises em torno do que poderia ser considerada uma versão brasileira da terceira via (e.g., ADRIÃO; PERONI, 2009; PERONI, 2013). Emergente na Inglaterra no fim dos anos 1990, a terceira via foi a opção que teve maior visibilidade no interregno entre a crise do welfare state e a consolidação do neoliberalismo. Com a terceira via, que Anthony Giddens inspirou e que Tony Blair quis pôr em prática como alternativa, pretendia-se resolver o suposto anacronismo do Estado enquanto mecanismo fundamental de regulação social, mas envolvendo a comunidade (sociedade civil, terceiro setor ou público náo estatal) e mobilizando igualmente o mercado para criar novos híbridos, como, por exemplo, as parcerias público-privadas. Um dos objetivos era amortecer, com alguma eficácia, os déficits de legitimidade política, sobretudo com a introdução de uma nova geração de políticas públicas (mais setoriais e particularistas) que procurasse dar conta do crescente aumento das desigualdades e assimetrias sociais.

Essa terceira via também não vingou como alternativa, tendo, pelo contrário, sido neutralizada rapidamente e absorvida pelo neoliberalismo que se tornou hegemônico, colocando, em decorrência disso, novos desafios à redefinição dos pilares tradicionais de regulação a nível nacional. Subsistiram, todavia, a nível interno, tendências para certa desestatização dos regimes políticos, refletindo uma possível (mas nem sempre convincente) transição do conceito (e da prática) de governo (government) para governação/governança (governance). Ou seja, a passagem de um modelo de regulação social e econômica assente no papel central do Estado para outro assente em parcerias e formas de associaçáo entre organizaçóes governamentais, paragovernamentais e não governamentais, nas quais o aparelho de Estado teria outras tarefas, nomeadamente de coordenação (ou de metarregulação). A nível mais amplo, ainda assim, as interaçóes complexas e assimétricas Estado-mercado-comunidade, inicialmente discutidas por diversos autores por referência à modernidade histórica, à soberania nacional e ao sistema de produção capitalista fordista, não desapareceram nem perderam importância, mas são hoje interaçóes que devem ser pensadas de modos distintos, diante do protagonismo de outros atores e instâncias, os quais vieram modificar e complexificar os processos tradicionais de regulação social (em sentido lato) e/ou fazer emergir e consolidar processos de regulação multiescalares, direta ou indiretamente referenciáveis ao espaço subnacional e, sobretudo, ao espaço internacional e supranacional, de forma mais específica mediante a ação estratégica de organizaçóes como o Banco Mundial, a Organização Mundial do Comércio, a União Europeia, a OCDE, as próprias agências de rating etc.

Em síntese, como já referi, e de forma mais visível a partir dos anos 1980, as mudanças políticas que surgiram, no início em alguns países centrais, e as suas recontextualizaçóes em número cada vez maior de países a 
nível mundial, tiveram repercussóes novas e diversas nos pilares de regulação social, primeiramente em relação à redefinição do papel do Estado e sua conexão (mesmo que indireta) a processos que de maneira crescente passaram a vincular ou condicionar as decisóes nacionais a outros níveis e instâncias, quer subnacionais, quer sobretudo internacionais ou supranacionais. Essas mudanças profundas, recordemos, ocorreram num período histórico na sequência de vários acontecimentos importantes, entre o fim da chamada Guerra Fria, a emergente globalização/internacionalização da economia e o impacto cada vez maior das novas tecnologias da informaçáo e comunicação. Como é sabido, a conjugação desses e de outros fatores traduziu-se num novo fôlego para a economia de mercado e para a democracia representativa, expandindo para novos espaços nacionais o sistema econômico capitalista, que se tornou a partir de então hegemônico. A esse propósito, ficou conhecida a expressão fim da história, recuperada pelo conhecido cientista político norte-americano Francis Fukuyama, querendo com isso significar que o liberalismo econômico seria o ápice da evoluçáo econômica da sociedade contemporânea, ou que o sistema demoliberal seria a única alternativa possível e desejável para delimitar os espaços de ação de uma nova ordem nacional e internacional. A realidade, porém, não deu razão a Fukuyama. $\mathrm{O}$ mundo tornou-se mais híbrido, complexo, ambíguo, líquido (na expressão tấo significativa de Zygmunt Bauman), e as experiências concretas em diferentes regióes do mundo continuaram a dar conta de vários desequilíbrios, inconsistências e até mesmo impossibilidades estruturais, na fórmula que supostamente pretendia ser a solução para as relaçóes entre os vários subsistemas (econômico, político, cultural etc.). Também por isso, no contexto mundial atual, bastante adverso, continuar a viabilizar as geraçóes de direitos fundamentais (já consagradas nas democracias mais avançadas), ampliar tais direitos para quem nunca os teve e acolher os novos direitos emergentes são tarefas que constituem um dos maiores desafios contemporâneos.

Por fim, faz-se um último apontamento sobre a relação entre regulação e emancipação. A história da relação contraditória do capitalismo com a democracia tem sido, em grande medida, a história da luta pelo equilíbrio entre o pilar da regulação e o pilar da emancipação, e isso tem sido um dos temas de autores táo importantes como Boaventura de Sousa Santos. No contexto atual, tendo em conta a realidade política e social (inesperada) de alguns países, a probabilidade do excesso de regulação estatal para desregular (que se poderá traduzir na radicalização da privatização e na reconfiguração de um Estado mínimo autoritário e coercitivo) implica necessariamente um recuo profundo da emancipação, o que certamente induzirá formas de resistência criativa no sentido da reposição do equilíbrio entre o pilar da regulação e o pilar da emancipação. Em situaçóes e conjunturas históricas facilmente identificáveis, algumas muito recentes, a desconfiança nos partidos e no 
funcionamento dos aparelhos político-administrativos (ainda que baseada em razôes concretas e com consequências nefastas) fez com que os movimentos sociais emancipatórios tivessem deixado de incorporar nos seus objetivos a democratização do Estado, polarizando a luta essencialmente fora da arena político-institucional - e isso facilitou a permanência de um Estado permeável a novos autoritarismos e formas de corrupção. Nesse sentido, os novos movimentos sociais que emergirem ou redefinirem suas estratégias não podem deixar de incorporar na sua agenda a luta pela redemocratização do próprio Estado, ou seja, a luta por formas mais justas de regulação. De modo paralelo, quer no contexto nacional, quer no contexto internacional, há que ter em conta que a relação entre regulação e emancipação passa por formas de dominação que se expressam em "padrôes emergentes de não regulação" (AVRITZER, 2002) - não regulaçâo que permite a manutenção de graves desigualdades e o adiamento de problemas humanitários, como é o caso do não cumprimento, por parte de alguns países hegemônicos, de importantes tratados e protocolos internacionais, já assinados e ratificados pelas partes. Nessa perspectiva, os novos acontecimentos ligados à crise econômica, às mudanças tecnológicas, às questóes ambientais e ecológicas, ao aumento das desigualdades, às emigraçóes e aos movimentos de refugiados pressionam para que se voltem a revalorizar e acionar mecanismos efetivos e eficazes de regulação, não apenas a nível nacional, mas também a nível internacional, estando aqui em evidência a necessidade de repensar o que se designa "governança regulatória" (KJAER; VETTERLEIN, 2018). Se quisermos extrapolar e convocar as questôes que têm hoje particular urgência, basta perceber as expectativas que se espera que sejam realizadas e articuladas em processos de regulação e solidariedade social (PROSSER, 2006) ou de governança global regulatória e democrática - expectativas que estão direcionadas, nomeadamente, para o cumprimento dos objetivos de desenvolvimento sustentável que fazem parte da Agenda 2030 da Organização das Naçôes Unidas, com particular centralidade para o papel da educação $(\mathrm{UNESCO}, 2017)^{5}$.

\section{Notas}

1. A título de exemplo, se considerarmos a importância da formação de profissionais para a função de avaliação, facilmente se percebe que muitos integrantes das comissôes de avaliação externas da A3ES não são propriamente especialistas em avaliação. Numa comparação com o Sinaes no Brasil, esse fato também pareceu revelador, dada a inexistência de "um corpo permanente de avaliadores especialistas", constatando-se que "a quase totalidade das mais de 20 mil avaliaçóes in loco de cursos de graduação do último decênio foi realizada por não especialistas (SGUISSARDI, 2013, p. 945). 
2. Tendo passado mais de uma década em relação à data da afirmação que se segue, admite-se que a situação tenha melhorado substantivamente. De qualquer modo, por alguma razão Avelãs Nunes (2007, p. 14) escreveu: "A verdade é que as autoridades reguladoras independentes não prestam contas perante nenhuma entidade legitimada democraticamente nem perante o povo soberano. Ora a prestação de contas é a pedra de toque da democracia. Sem ela, temos a morte da politica. E temos uma ameaça à democracia, tal como a entendemos" (grifo do autor).

3. Um interessante debate, com base na contribuição de autores de referência no campo dos estudos da administração educacional em Portugal, tem posto em confronto argumentos que acentuam a transição para modos de regulação pós-burocráticos e argumentos que, pelo contrário, enfatizam que não apenas a regulação burocrática não acabou como há claras evidências de uma radicalização hiperburocrática. Sobre essa segunda perspectiva, ver Lima (2016).

4. É, no entanto, uma questão complexa e discutível que não me parece ter o aval de um dos especialistas de referência no campo, o qual, a esse propósito, escreve: “'Accountability' is not the same as 'regulation' or 'control', which are essentially forward-looking mechanisms of influencing behaviour, whereas accountability is retrospective, inquiring into actions that have already taken place. Systems of control and regulation often include accountability mechanisms, as when people are held accountable for breaking the law or for acting unprofessionally. But they are not identical to these mechanisms" (MULGAN, 2002, p. 3).

5. Um importante trabalho sobre as mudanças nos modos de regulação e a produção social de desigualdades em educação foi levado a cabo por uma equipe integrada por investigadores de vários países europeus, entre os quais Portugal, com participação de João Barroso e outros colegas, num projeto coordenado por Christian Maroy (2004).

\section{Referências}

ADRIÃO, T.; PERONI, V. A educação pública e a sua relação com o setor privado. Implicaçóes para a democracia educacional. Retratos da Escola, Brasília, v. 3, n. 4, p. 107116, jan.-jun. 2009. http://dx.doi.org/10.22420/rde.v3i4.105

AFONSO, A. J. Ensaio sobre a accountability no ensino superior em Portugal (19762013). Discursos, formas parcelares e modelo atual. In: SOUSA, J. V. (org.). Educaçáa Superior: cenários, impasses e propostas. Campinas: Autores Associados, 2013a. p. 13-59.

AFONSO, A. J. Mudanças no Estado-avaliador: comparativismo internacional e teoria da modernização revisitada. Revista Brasileira de Educação, Rio de Janeiro, v. 18, n. 53, p. 267-284, abr./jun. 2013b. http://dx.doi.org/10.1590/S1413-24782013000200002

ANTUNES, F. Globalização e europeização das políticas educativas. Percursos, processos e metamorfoses. Sociologia, Problemas e Práticas, n. 47, p. 125-143, 2005. 
ANTUNES, F. O espaço europeu de ensino superior para uma nova ordem educacional? Educaçáo Temática Digital, Campinas, n. 9, p. 1-28, dez. 2007. https://doi.org/10.20396/ etd.v9in.esp..725

AVRITZER, L. Globalização e espaços públicos: a não regulação como estratégia de hegemonia global. Revista Crítica de Ciências Sociais, n. 63, p. 107-121, out. 2002.

BARROSO, J. A transversalidade das regulaçóes em educação: modelo de análise para o estudo das políticas educativas em Portugal. Educação \& Sociedade, Campinas, v. 39, n. 145, p. 1075-1097, out./dez. 2018. http://dx.doi.org/10.1590/es0101-73302018214219

BARROSO, J. O Estado, a educação e a regulação das políticas públicas. Educação \& Sociedade, Campinas, v. 26, n. 92, p. 725-751, out. 2005.

BAUMAN, Z. Modernidade Líquida. Rio de Janeiro: Jorge Zahar, 2001.

BECK, U. Risk Society.Towards a new modernity. London: Sage, 1992.

BIANCHETTI, L.; SGUISSARDI, V. Da Universidade à Commoditycidade. Campinas: Mercado das Letras, 2017.

BLAIR, T. La Tercera Vía. Madrid: Santillana/Ediciones El País, 1998.

BRESSER-PEREIRA, L.C.; NURIA CUNILL GRAU, N. C. (orgs.). O Público NáoEstatal na Reforma do Estado. Rio de Janeiro: Editora FGV, 1999.

CARVALHO, L. M. Intensificação e sofisticação dos processos de regulação transnacional em educaçáo: O caso do programa internacional de avaliaçáo de estudantes. Educaçáo \& Sociedade, Campinas, v. 37, n. 136, p. 669-683, jul./set. 2016. http://dx.doi.org/10.1590/ es0101-73302016166669

CARVALHO, L. M.; COSTA, E. Avaliação externa das escolas em Portugal: atores, conhecimentos, modos de regulação. Revista Brasileira de Política e Administração da Educaçáo, v. 33, n. 3, p. 685-705, set./dez. 2017. https://doi.org/10.21573/ vol33n32017.79302

CHOMSKY, N. O Novo Humanismo Militar. Liçóes de Kosovo. Lisboa: Campo das Letras, 2002.

FALABELLA, A.; VEGA, L. F. Políticas de responsabilización por desempeño escolar: Un debate a partir de la literatura internacional y el caso chileno. Estudios Pedagógicos, v. 42, n. 2, p. 395-413, 2016. http://dx.doi.org/10.4067/S0718$\underline{07052016000200023}$

GARCÍA-JUANATEY, A. et al. Las agencias públicas en España: percepciones sobre autonomía y rendición de cuentas. Revista Española de Ciencia Política, n. 43, p. 6182, 2017. https://doi.org/10.21308/recp.43.03

GIDDENS, A. Para uma Terceira Via. Lisboa: Editorial Presença, 1999.

JORDANA, J.; BIANCULLI, A.; FERNÁNDEZ-I-MARÍN, X. When Accountability Meets Regulation. In: Bianculli, A.; Fernández-i-Marín, X.; Jordana, J. (orgs.). Accountability and Regulatory Governance. Londres: Palgrave/MacMillan, 2015. p. 1-22. 
KJAER, P. F; VETTERLEIN, A. Regulatory governance: rules, resistance and responsibility. Contemporary Politics, v. 24, n. 5, p. 497-506, 2018. https://doi.org/10. $\underline{1080 / 13569775.2018 .1452527}$

LIMA, L. C. Evaluacíon hiperburocrática. Profesorado, v. 20, n. 3, p. 87-118, 2016.

LIMA, L. C. Privatização lato sensu e impregnação empresarial na gestão da educação pública. Currículo sem Fronteiras, v. 18, n. 1, p. 129-144, jan./abr. 2018.

LODGE, M.; STIRTON, L. Accountability in the regulatory State. In: BALDWIN, R.; CAVE, M.; LODGE, M. (orgs.). The Oxford Handbook of Regulation. Oxford: Oxford University Press, 2010. p. 64-85.

MAJONE, G. The regulatory state and its legitimacy problems. West European Politics, v. 22, n. 1, p. 1-24, 1999. https://doi.org/10.1080/01402389908425284

MAROY, C. (coord.). Regulation and Inequalities in European Education Systems. Final Report. 2004. Disponível em: <https://www.researchgate.net/profile/Christian_ Maroy/publication/44837136 Regulation and inequalities in European education systems final report/links/5492e7880cf225673b3e1052/Regulation-and-inequalitiesinEuropean-education-systems-final-report.pdf>. Acesso em: 8 jan. 2019.

MULGAN, R. Accountability Issues in the New Model of Governance. Discussion Paper No.91. 2002. Disponível em: <https://core.ac.uk/download/pdf/156617012.pdf>. Acesso em: 8 jan. 2019.

NEAVE, G. The evaluative state reconsidered. European Journal of Education, v. 33, n. 3, p. 265-284, 1998.

NOZICK, R. Anarquia, Estado e Utopia. Lisboa: Edições 70, 2009.

NUNES, A. Breve reflexão sobre o chamado estado regulador. Revista Seqüência, São Carlos, v. 28, n. 54, p. 9-18, jul. 2007. https://doi.org/10.5007/\%25x

OLSEN, J. P. Democratic accountability and the changing European political order. European Law Journal, v. 24, n. 1, p. 77-98, jan. 2018. https://doi.org/10.1111/ eulj. 12261

ORGANIZAÇÃO DAS NAÇÓES UNIDAS PARA A EDUCAÇÃO, A CIÊNCIA E A CULTURA (UNESCO). Educaçáo para os Objetivos do Desenvolvimento Sustentável. Paris: Unesco, 2017.

PERONI, V. As relaçóes entre o público e o privado nas políticas educacionais no contexto da terceira via. Currículo sem Fronteiras, v. 13, n. 2, p. 234-255, maio/ago. 2013.

PORTUGAL. Decreto-Lei no 369/2007. Diário da República n.o 212, Série I de 2007-11-05.

PROSSER, T. Regulation and social solidarity. Journal of Law and Society, v. 33, n. 3, p. 364-387, set. 2006. https://doi.org/10.1111/j.1467-6478.2006.00363.x

REIS, I. Governança e regulação da educação. Perspetivas e conceitos. Educaçáo, Sociedade \& Culturas, n. 39, p. 101-118, 2013. 
SANTOS, B. S. Renovar a Teoria Crítica e Reinventar a Emancipaçáo Social. São Paulo: Boitempo, 2007.

SGUISSARDI, V. Regulação estatal e desafios da expansão mercantil da educação superior. Educação \& Sociedade, Campinas, v. 34, n. 124, p. 943-960, jul./set. 2013. http:// dx.doi.org/10.1590/S0101-73302013000300015

YEUNG, K. The Regulatory State. In: Baldwin, R.; Cave, M.; Lodge, M. (orgs.). The Oxford Handbook of Regulation. Oxford: Oxford University Press, 2010. p. 64-85.

ZUBOFF, S. Um capitalismo de vigilância. Le Monde Diplomatique, Lisboa, II série, n. 147, p. 11-13, 2019.

\section{SOBRE O AUTOR}

Almerindo Janela Afonso é sociólogo, doutor em Educação e professor do Instituto de Educação da Universidade do Minho (Portugal). Foi presidente da Sociedade Portuguesa de Ciências da Educação e membro do Conselho Nacional de Educação.

Recebido em 18 de fevereiro de 2019.

Aceito em 30 de abril de 2019. 